\title{
Finite Element Analysis of Formability of Pyramid- al Cups Fabricated from AA1100-H18 Alloy
}

\author{
T. Santhosh Kumar ${ }^{1}$, A. Chennakesava Reddy ${ }^{2}$ \\ ${ }^{1}$ PG student Department of Mechanical Engineering, JNTUH College of Engineering, Kukatpally, Hyderabad - 500 085, Telangana, India \\ ${ }^{2}$ Professor, Department of Mechanical Engineering, JNTUH College of Engineering, Kukatpally, Hyderabad - 500 085, Telangana, India
}

\begin{abstract}
The purpose of the present project work was to understand the formability of AA1100-H18 alloy to fabricate conical cups using single point incremental forming (SPIF) process. The finite element analysis has been carried out to model the single point incremental forming process using ABAQUS software code. The process parameters of SPIF were sheet thickness, step depth, tool radius and coefficient of friction. The process parameters have been optimized using Taguchi techniques. The major process parameters influencing the SPIF of pyramidal cups were sheet thickness and step depth of incremental forming process.
\end{abstract}

Keywords: AA1100-H18 alloy, single point incremental forming, pyramidal cups, finite element analysis, step depth, tool radius, sheet thickness, coefficient of friction

\section{Introduction}

In incremental sheet forming process, sheet is deformed into desired shape by a rigid spherical tool without dies. The process is carried out on a CNC machine. For a given shape of the product tool path is controlled by a part program. In recent years many researchers focused on study of deformation mechanism in single point incremental forming process (SPIF) through analytical [1, 2] and numerical models [3, 4]. Most of the numerical studies in incremental forming concentrated on prediction of formability and thinning.

Using finite element methods, forming limit diagrams (FLD) were predicted for several materials such as AA1050 alloy [5], AA1070 alloy [6], AA1080 alloy [7], AA1100 alloy [8], AA2014 alloy [9], AA2017 alloy [10], AA2024 alloy [11], AA2219 alloy [12], AA2618 alloy [13], AA3003 alloy [14], AA5052 alloy [15], AA5039 alloy [16], Ti-Al-4V alloy [17], EDD steel [18] and gas cylinder steel [19].

In the present work elastic-plastic scheme based on the incremental theory of plasticity was employed to simulate SPIF process instead of the conventional flow theory of plasticity minimize the computational time. The present work was to study the formability of pyramidal cups of AA1100 alloy using SPIF. For this purpose the design of experiments was executed as per Taguchi technique. The process parameters of SPIF were sheet thickness, step depth, tool radius and coefficient of friction.

Table 1: Process parameters and levels

\begin{tabular}{|c|c|c|c|c|}
\hline Factor & Symbol & Level-1 & Level -2 & Level -3 \\
\hline Sheet thickness, mm & A & 1.0 & 1.2 & 1.5 \\
\hline Step depth, mm & B & 0.50 & 0.75 & 1.00 \\
\hline Tool radius, mm & C & 4.0 & 5.0 & 6.0 \\
\hline Coefficient of friction & D & 0.05 & 0.10 & 0.15 \\
\hline
\end{tabular}

\section{Finite Element Modeling}

In the present work, ABAQUS (6.14) software code was used for the numerical simulation of SPIF process to fabricate conical cups. The material was AA1100 alloy. The SPIF process parameters were chosen at three levels as summarized in table 1 . The orthogonal array (OA), L9 was preferred to carry out experimental and finite element analysis (FEA) as given in table 2 .

Table 2: Orthogonal Array (L9) and control parameters

\begin{tabular}{|c|c|c|c|c|}
\hline Treat No. No. & A & B & C & D \\
\hline 1 & 1 & 1 & 1 & 1 \\
\hline 2 & 1 & 2 & 2 & 2 \\
\hline 3 & 1 & 3 & 3 & 3 \\
\hline 4 & 2 & 1 & 2 & 3 \\
\hline 5 & 2 & 2 & 3 & 1 \\
\hline 6 & 2 & 3 & 1 & 2 \\
\hline 7 & 3 & 1 & 3 & 2 \\
\hline 8 & 3 & 2 & 1 & 3 \\
\hline 9 & 3 & 3 & 2 & 1 \\
\hline
\end{tabular}
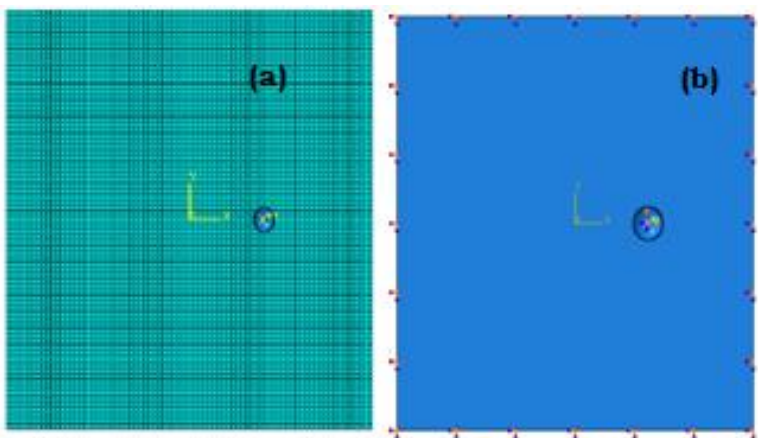

Figure 1: Finite element modeling: (a) mesh generation and (b) boundary conditions.

The sheet and tool geometry were modeled as deformable and analytical rigid bodies, respectively, using ABAQUS. They were assembled as frictional contact bodies. The sheet material was meshed with S4R shell elements (figure 1a). The fixed boundary conditions were given to all four edges of the sheet as shown in figure $1 \mathrm{~b}$. The boundary conditions for tool were $\mathrm{x}, \mathrm{y}, \mathrm{z}$ linear movements and rotation about the axis of tool [20]. True stress-true strain experimental data were loaded in the tabular form as material properties. The tool path geometry was generated using CAM software [21] was imported to the ABAQUS as shown in figure 2. The elastic-plastic deformation analysis was carried out for the

\section{Volume 5 Issue 6, June 2016 www.ijsr.net}




\section{International Journal of Science and Research (IJSR) \\ ISSN (Online): 2319-7064}

Index Copernicus Value (2013): 6.14 | Impact Factor (2015): 6.391

equivalent stress, strain and strain rates and thickness variation.

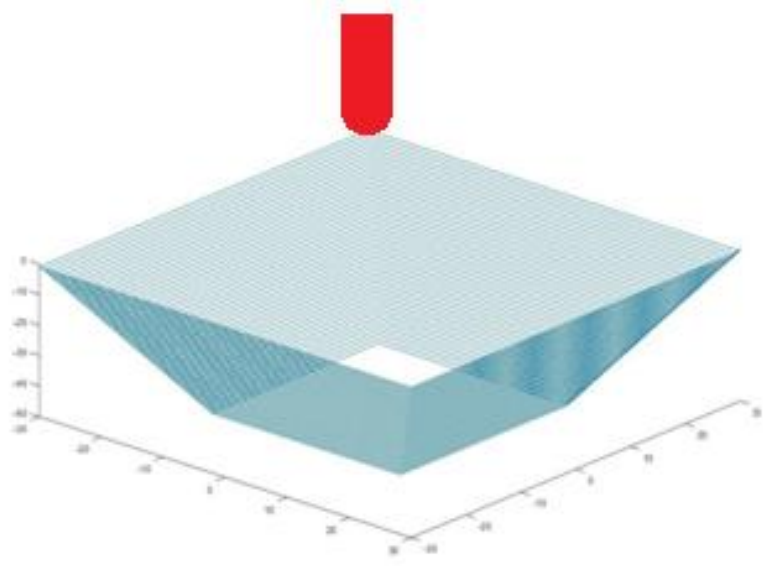

Figure 2: Tool path generation.

\section{Results and Discussion}

F-tests arises by considering a decomposition of the variability in a collection of data in terms of sums of squares. In this work, the Fisher's test was confirmed to accept all the parameters (A, B, C and D) at $90 \%$ confidence level. If the percentage contribution of process parameters is less than $10 \%$, they are considered as less significant.

\subsection{Influence of process parameters on effective stress}

Table -3 gives the ANOVA (analysis of variation) summary of effective stress data. The most significant contributions are of step depth $(53.23 \%)$ and sheet thickness $(34.81 \%)$. The coefficient of friction makes the least contribution towards the effective stress. The tool radius contributes only $9.01 \%$ of variation in the effective stress.

Table 3: ANOVA summary of the effective stress

\begin{tabular}{|c|c|c|c|c|c|c|c|c|}
\hline Source & Sum 1 & Sum 2 & Sum 3 & $S S$ & $v$ & $V$ & $F$ & $P$ \\
\hline A & 856.7 & 841.7 & 825.4 & 163.37 & 1 & 163.37 & 32674 & 34.81 \\
\hline B & 822.2 & 840.7 & 860.9 & 249.77 & 1 & 249.77 & 49954 & 53.23 \\
\hline C & 839.4 & 850 & 834.4 & 42.3 & 1 & 42.3 & 8460 & 9.01 \\
\hline D & 845.8 & 841.3 & 836.7 & 13.8 & 1 & 13.8 & 2760 & 2.94 \\
\hline e & & & & 0.02 & 4 & 0.005 & 1 & 0 \\
\hline T & 3364.1 & 3373.7 & 3357.4 & 469.26 & 8 & & & 100 \\
\hline
\end{tabular}

Note: $S S$ is the sum of square, $v$ is the degrees of freedom, $V$ is the variance, $F$ is the Fisher's ratio, $P$ is the percentage of contribution and $T$ is the sum squares due to total variation.
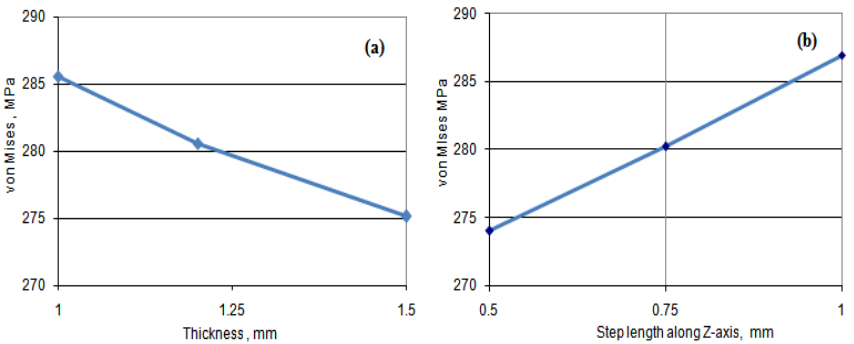

Figure 3: Influence of process parameters on von Mises stress
Figure 3 a presents the effective stress as a function of sheet thickness. The effective stress was continuously decreased with sheet thickness. For plastic deformation, the bearing area increases with the sheet thickness. When a constant force applied on the sheet during incremental forming process for a given step depth, the effective stress gets decreased with increase of sheet thickness. Figure $3 \mathrm{~b}$ describes the effective stress as a function of step depth. The effective stress was increased with step depth in the downward movement of the tool. For a given sheet thickness, the forced required per unit deformation increases with steep depth of the tool.

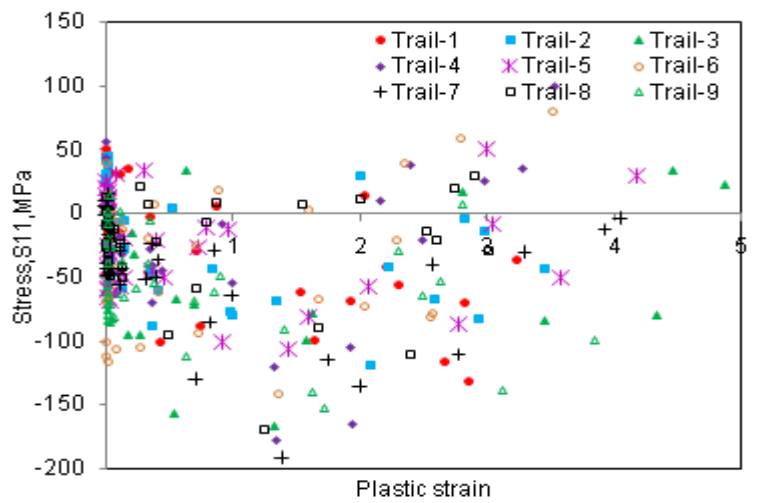

Figure 4: Effect of process parameters on $S_{11}$.

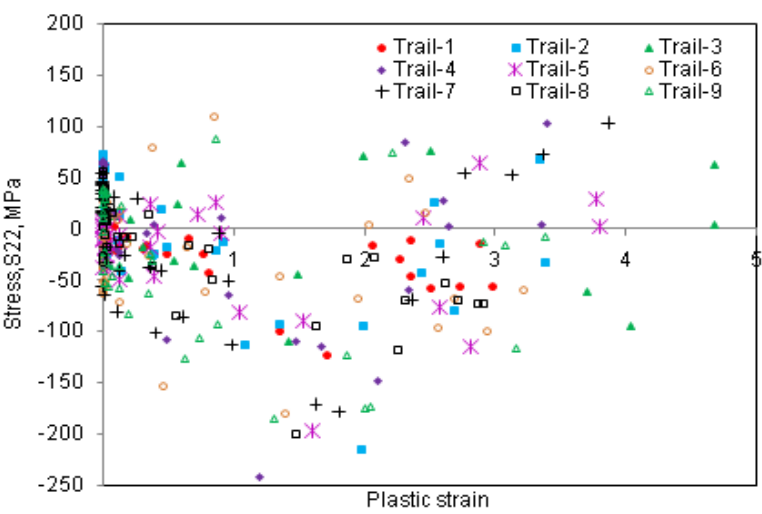

Figure 5: Effect of process parameters on $S_{22}$.

The principal stresses $S_{11}, S_{22}$ and shear stress $S_{12}$ are shown in figure 4, 5 and 6 respectively. The density of compressive stresses induced in the sheet are higher in number than the tensile stresses for the strain less than 4.0. The shear stress developed in the blank sheet is less than $50 \%$ of $S_{11}$ or $S_{22}$.

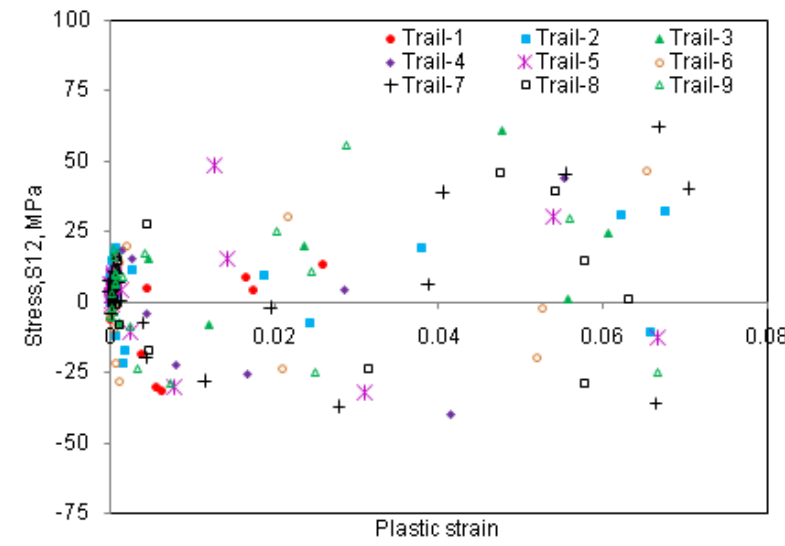

Figure 6: Effect of process parameters on $S_{12}$.

\section{Volume 5 Issue 6, June 2016 www.ijsr.net}




\section{International Journal of Science and Research (IJSR) \\ ISSN (Online): 2319-7064}

Index Copernicus Value (2013): 6.14 | Impact Factor (2015): 6.391

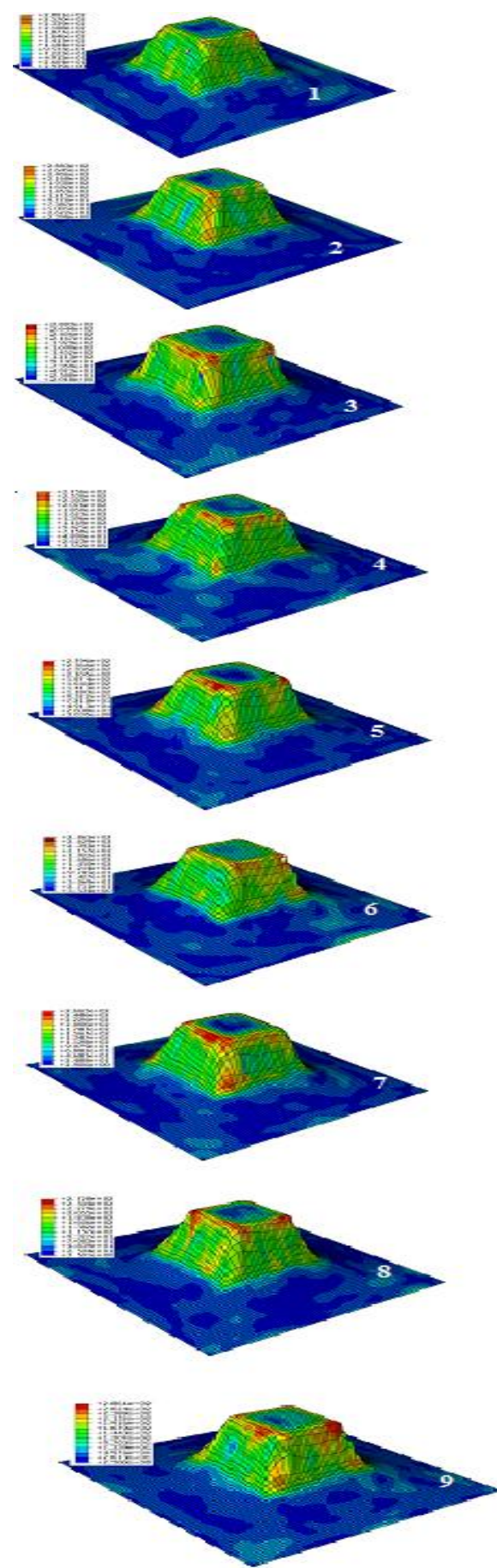

Figure 7: Raster images of von Mises stress in the cups.

For the trials 1, 2 and 3, the von Mises stresses are, respectively, 280.1MPa, 288.3 MPa and 288.3 MPa, For the trials 4, 5 and 6, the von Mises stresses are, respectively, 275.6 $\mathrm{MPa}, 279.6 \mathrm{MPa}$ and $286.5 \mathrm{MPa}$. For the trials 7, 8 and 9, the von Mises stresses are, respectively, 266.5 $\mathrm{MPa}, 272.8 \mathrm{MPa}$ and 286.1 MPa (figure 7).

\subsection{Influence of parameters on strain rate}

The ANOVA summary of the strain rate is given in Table 4. The percent contribution column establishes the most signif- icant process parameters are step depth, coefficient of friction and sheet thickness. Their contributions are $46.20 \%$, $29.00 \%$, and $17.99 \%$ towards variation in the strain rate. The less significant process parameter is tool radius.

Table 4: ANOVA summary of the strain rate

\begin{tabular}{|c|c|c|c|c|c|c|c|c|}
\hline Source & Sum 1 & Sum 2 & Sum 3 & $S S$ & $v$ & $V$ & $F$ & $P$ \\
\hline A & 16.235 & 9.922 & 19.348 & 15.38 & 1 & 15.38 & 6980.597 & $\begin{array}{c}17.9 \\
9\end{array}$ \\
\hline B & 23.976 & 11.804 & 9.725 & 39.51 & 1 & 39.51 & 17932.6 & 46.2 \\
\hline C & 16.681 & 11.757 & 17.067 & 5.84 & 1 & 5.84 & 2650.63 & 6.83 \\
\hline D & 17.416 & 19.824 & 8.265 & 24.8 & 1 & 24.8 & 11256.1 & 29 \\
\hline e & & & & -0.00881 & 4 & -0.0022 & 1 & 0 \\
\hline T & 74.308 & 53.307 & 54.405 & 85.52119 & 8 & & & 100 \\
\hline
\end{tabular}
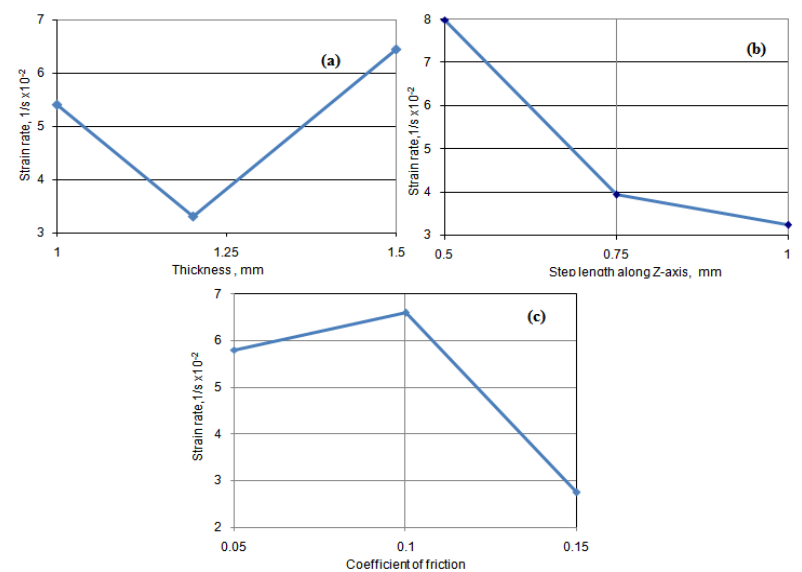

Figure 8: Influence of process parameters on strain rate.

As observed from figure 8a the strain rate was low for sheet thickness of $1.2 \mathrm{~mm}$. However, the strain rate was higher for the sheet thickness of $1.5 \mathrm{~mm}$ than those for $1.0 \mathrm{~mm}$ and 1.2 $\mathrm{mm}$ thicknesses. The strain rate was decreased with increase of step depth (figure 8b). For smaller step size local deformation plays an important role than stretching. The strain rate was found to be high for coefficient of friction of 0.1(figure $8 \mathrm{c})$. The cup formation depends on the shear stress developed during the plastic deformation of sheet material. When the frictional shear stress, reaches the limiting shear stress of the sheet material, the material undergoes plastic deformation. From this point the frictional shear stress does not increase and has the value of the limiting shear stress and thereby limiting the coefficient of friction. In this case the limiting value of coefficient of friction was 0.1 . Hence, at each contact spot of tool with sheet, the local strain determines the coefficient of friction.

\subsection{Influence of parameters on thickness reduction}

The ANOVA summary of the thickness reduction is given in Table 5. In the decreasing order of contribution, tool radius, step depth and sheet thickness deliver, respectively, $45.43 \%$, $27.71 \%$ and $19.38 \%$ towards variation in the thickness reduction. 
International Journal of Science and Research (IJSR)

ISSN (Online): 2319-7064

Index Copernicus Value (2013): 6.14 | Impact Factor (2015): 6.391

Table 5: ANOVA summary of the thickness reduction

\begin{tabular}{|c|c|c|c|c|c|c|c|c|}
\hline Source & Sum 1 & Sum 2 & Sum 3 & SS & v & V & F & P \\
\hline A & 235.526 & 235.376 & 228.45 & 10.9 & 1 & 10.9 & 3247.4 & 19.38 \\
\hline B & 230.029 & 230.633 & 238.68 & 15.58 & 1 & 15.58 & 4641.697 & 27.71 \\
\hline C & 226.848 & 233.281 & 239.22 & 25.54 & 1 & 25.54 & 7609.046 & 45.43 \\
\hline D & 235.491 & 230.496 & 233.36 & 4.18 & 1 & 4.18 & 1245.333 & 7.43 \\
\hline e & & & & 0.013426 & 4 & 0.003357 & 1 & 0 \\
\hline T & 927.894 & 929.788 & 939.73 & 56.21 & 8 & & & 100 \\
\hline
\end{tabular}

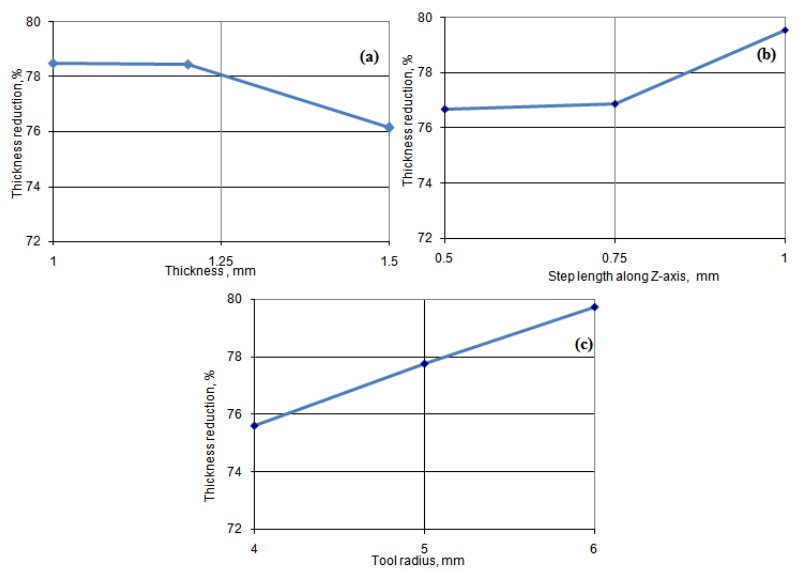

Figure 9: Influence of process parameters on thickness reduction

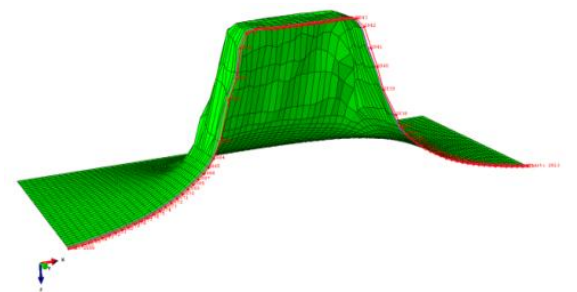

Figure 10: Location of thickness reduction in the deformed cup
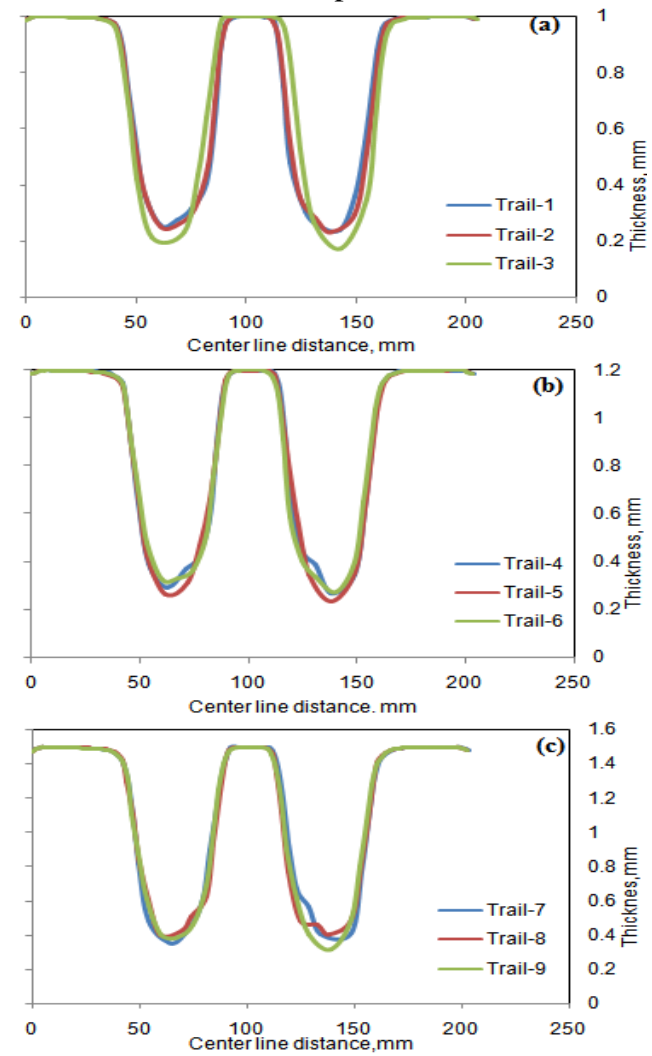

Figure 11: Effect of process parameters on thickness reduction
The reduction sheet thickness is the indicative of severity in the plastic deformation. The reduction of sheet thickness was very low for large sheet thickness as seen from figure 9a. The reduction in thickness was increased with increase of steep depth (figure 9b). Also, the thickness reduction was increased with tool radius (figure 9c). As mentioned earlier with regard to strain rate, the thickness reduction depends upon the local plastic deformation. The reduction of thickness was considered at the center-line of the deformed cup as shown in figure 10. As observed from figure 11, the majority of thickness reduction takes place in the upper part walls of the cup but not in the flange or bottom or lower part of walls of the cup. The thickness built-up occurs in lower part of walls of the pyramidal cup.

\subsection{Formability of SPIF process}

The formability diagrams of the cups are shown in figures 12, 13 and 14. During initial stages of SPIF, the shear and compressive stresses were dominating the formability of conical cups of AA1100 alloy. At later stages of plastic deformation the simple tension is highly predominant resulting the stretching of sheet. This phenomenon is same for all the trials. The major strain limit for the formation of cup without fracture should not exceed 1.0 for all the cases as compared with figure 14. Superplastically deformed material gets thinner in a very uniform manner, rather than forming a "neck" (a local narrowing) that leads to fracture. The range of strain rate for incremental deep drawing of AA110 alloy was 0.02 to $0.1 \mathrm{~s}^{-1}$. The superplastic behavior is only predicted for strain rates in the range $2 \times 10^{-4} \mathrm{~s}^{-1}$ to $5 \times 10^{-1} \mathrm{~s}^{-1}$. The strain rate exponent, $\mathrm{m}$, is on the order of 0.1 or less for metals deforming by dislocation glide, far below the level of $\mathrm{m}=0.3$, which corresponds roughly to an elongation of $300 \%$.

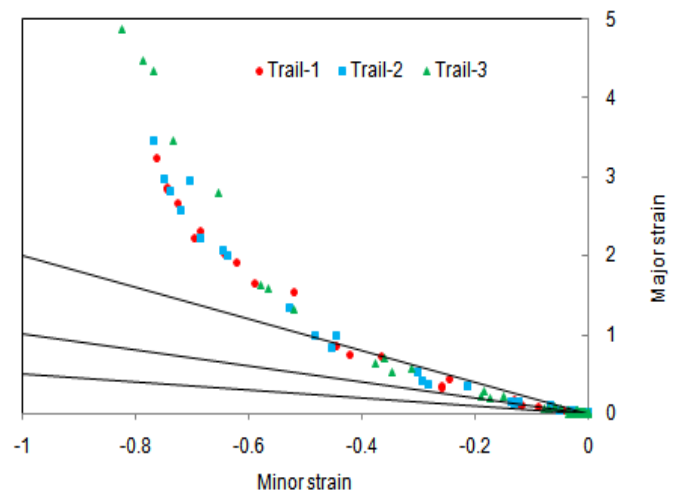

Figure 12: Forming limit diagrams for trials 1, 2 and 3

\section{Volume 5 Issue 6, June 2016 www.ijsr.net}


International Journal of Science and Research (IJSR)

ISSN (Online): 2319-7064

Index Copernicus Value (2013): 6.14 | Impact Factor (2015): 6.391

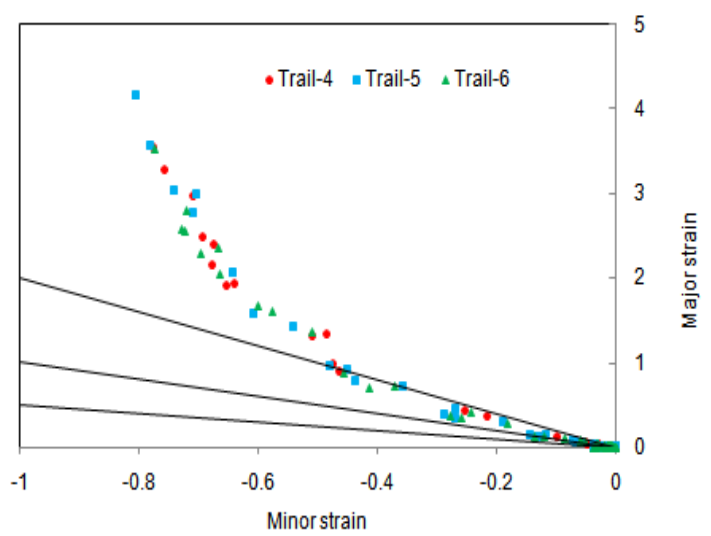

Figure 13: Forming limit diagrams for trials 4, 5 and 6

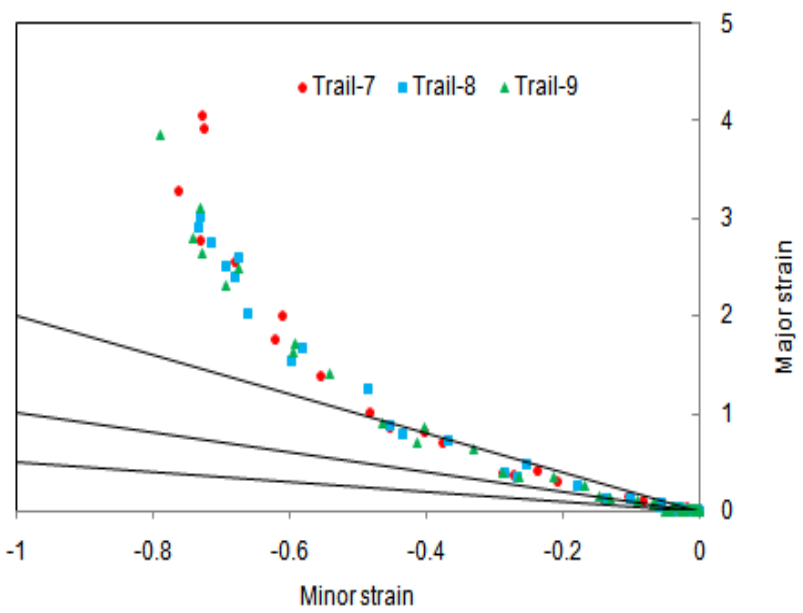

Figure 14: Forming limit diagrams for trials 7, 8 and 9.

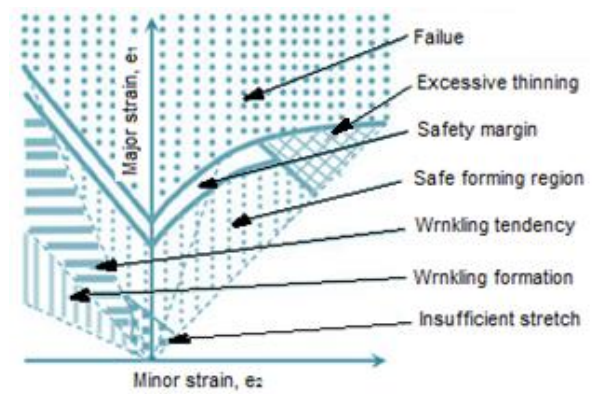

Figure 15: Forming limit diagram of deep drawing process.

\section{Conclusions}

The major SPIF process parameters which influence the formability of truncated pyramidal cups of AA1100-H18 alloy were sheet thickness and step depth of incremental forming process. The strain rate developed during the incremental forming of conical cups was within the limits of superplasticity.

\section{Acknowledgements}

The author acknowledges with thanks University Grants Commission (UGC) - New Delhi for sectioning R\&D project.

\section{References}

[1] Iseki, An approximate deformation analysis and FEM analysis of the incremental bulging of sheet metal using spherical rollers, Journal of Materials Processing Technology, 111, 2001, pp. 150-154.

[2] M. B. Silva, M. Skjoedt, P.A.F. Martins, N. Bay, Numerical simulation of incremental forming of sheet metal, Journal of Materials Processing Technology, 199, 2008, pp.163-172.

[3] Y. Minoru, G. Manabu S. Atsumi, Numerical simulation of incremental forming of sheet metal, Journal of Materials Processing Technology, 199, 2008, pp.163-172.

[4] R. Feng, C. Zhen, Z. Cedric Xia, S. Todd, Z. Li, X. Zhu, Process modeling of freeform incremental formingLsDyna, 11th International Ls-Dyna users conference, 2010, pp. 10.1-10.5.

[5] A. C. Reddy, "Homogenization and Parametric Consequence of Warm Deep Drawing Process for 1050A Aluminum Alloy," Validation through FEA, International Journal of Science and Research, 4 (4), pp. 20342042, 2015.

[6] K. Chandini and A. C. Reddy, "Finite Element Analysis of Warm Deep Drawing Process for Pyramidal Cup of AA1070 Aluminum Alloy," International Journal of Advanced Research, 3(6), pp. 1325-1334, 2015.

[7] B. Yamuna and A. C. Reddy, "Finite Element Analysis of Warm Deep Drawing Process for Conical Cup of AA1080 Aluminum Alloy," International Journal of Advanced Research, 3(6), pp. 1309-1317, 2015.

[8] T. Srinivas and A. C. Reddy, "Finite Element Analysis of Warm Deep Drawing Process for Rectangular Cup of AA1100 Aluminum Alloy," International Journal of Advanced Research, 3(6), pp. 1383-1391, 2015.

[9] A. C. Reddy, "Parametric Optimization of Warm Deep Drawing Process of 2014T6 Aluminum Alloy Using FEA," International Journal of Scientific \& Engineering Research, 6(5), pp.1016-1024, 2015.

[10]A. C. Reddy, "Finite Element Analysis of Warm Deep Drawing Process for 2017T4 Aluminum Alloy: Parametric Significance Using Taguchi Technique," International Journal of Advanced Research, 3(5), pp. 1247$1255,2015$.

[11] A. C. Reddy, "Parametric Significance of Warm Drawing Process for 2024T4 Aluminum Alloy through FEA," International Journal of Science and Research, 4(5), pp. 2345-2351, 2015.

[12]A. C. Reddy, "Formability of High Temperature and High Strain Rate Superplastic Deep Drawing Process for AA2219 Cylindrical Cups," International Journal of Advanced Research, 3(10), pp. 1016-1024, 2015.

[13]A. C. Reddy, "High temperature and high strain rate superplastic deep drawing process for AA2618 alloy cylindrical cups," International Journal of Scientific Engineering and Applied Science, 2(2), pp. 35-41, 2016.

[14]A. C. Reddy, "Practicability of High Temperature and High Strain Rate Superplastic Deep Drawing Process for AA3003 Alloy Cylindrical Cups," International Journal of Engineering Inventions, 5(3), pp. 16-23, 2016.

[15] A. C. Reddy, "Suitability of High Temperature and High Strain Rate Superplastic Deep Drawing Process for AA5052 Alloy," International Journal of Engineering 


\section{International Journal of Science and Research (IJSR) \\ ISSN (Online): 2319-7064}

Index Copernicus Value (2013): 6.14 | Impact Factor (2015): 6.391

and Advanced Research Technology, 2(3), pp. 11-14, 2016.

[16] A. C. Reddy, "High temperature and high strain rate superplastic deep drawing process for AA5049 alloy cylindrical cups," International Journal of Engineering Sciences \& Research Technology, 5(2), pp. 261-268, 2016.

[17] A.C. Reddy, "Finite element analysis of reverse superplastic blow forming of Ti-Al-4V alloy for optimized control of thickness variation using ABAQUS," Journal of Manufacturing Engineering, 1(1), pp.6-9, 2006.

[18] A. C. Reddy, T. K. K. Reddy, M.Vidya Sagar, "Experimental characterization of warm deep drawing process for EDD steel," International Journal of Multidisciplinary Research \& Advances in Engineering, 4(3), pp.5362, 2012.

[19] A. C .Reddy, "Evaluation of local thinning during cup drawing of gas cylinder steel using isotropic criteria," International Journal of Engineering and Materials Sciences, 5(2), pp.71-76, 2012.

[20] Chennakesava, R. Alavala, "CAD/CAM: Concepts and Applications," PHI Learning Pvt. Ltd, 2008:

[21] Chennakesava R. Alavala, "Finite element methods: Basic Concepts and Applications, PHI Learning Pvt. Ltd., 2008.

Volume 5 Issue 6, June 2016 www.ijsr.net 